\title{
EFFECT OF INOCULATION WITH PIRIFORMOSPORA INDICA AND SEBACINA VERMIFERA ON GROWTH OF SELECTED BRASSICACEAE PLANTS UNDER GREENHOUSE CONDITIONS
}

\author{
Hossein KARI DOLATABADI*1, Ebrahim MOHAMMADI GOLTAPEH ${ }^{2}$ \\ ${ }^{1}$ Department of Plant Protection, University College of Agriculture and Natural Resources, \\ University of Tehran, Karaj, Iran \\ ${ }^{2}$ Department of Plant Pathology, Faculty of Agriculture, Tarbiat Modarres University, Tehran, Iran
}

Received: August 14 2013; Accepted: December 10, 2013

\begin{abstract}
The effect of inoculation of two root-colonizing basidiomycete fungi Piriformospora indica and Sebacina vermifera on the host plants from the family Brassicaceae (Brassica oleracea, B. napus, B. nigra, Lepidium sativum, Descurainia sophia and Matthiola incana) was studied in a pot experiment. Both fungi were able to colonize all plant species tested but with different efficiency. Colonized plants reacted with increase of fitness, bigger leaves and more side shoots. Plant heights of five inoculated species were higher than of uninoculated controls. Five species had higher dry weight of shoots and four had higher dry weights of roots. The highest stimulation was stated for B. oleracea and the lowest for $L$. sativum. It can be connected with the intensity of root colonization, which was greater in $B$. oleracea. In most cases both fungi influenced growth and dry weight of plants similarly but B. nigra and D. sophia were stimulated more by $P$. indica and B. napus by $S$. vermifera.
\end{abstract}

Key words: Brassicaceae, Piriformospora indica, Sebacina vermifera, plant height, dry weight

\section{INTRODUCTION}

The family Brassicaceae comprises approximately 338 genera and 3709 species (Warwick \& Al-Shehbaz 2006), and includes several important economic crops (e.g., Brassica spp., Lepidium sativum, Matthiola spp., etc.) used as a source of oil, mustard condiments, vegetables, forage and fodder. The Brassicaceae are usually found in temperate regions of the northern hemisphere, especially Mediterranean regions, and colonize a great variety of habitats including the arctic and alpine regions and some of the most climatically inhospitable deserts, though it is poorly represented in the tropics (Hedge 1976).

Piriformospora indica (Verma et al. 1998) and Sebacina vermifera (Warcup 1988) are filamentous fungi belonging to the order Sebacinales. Weiss et al. (2004) suggest that Sebacinales represent one of the earliest Basidiomycete lineages with mycorrhi- zal members, which can form ecto-, ericoid and orchid mycorrhiza. $P$. indica was first isolated from the rhizosphere of Prosopis julifora and Zizyphus nummularia in Rajasthan, India, and form a mutualistic symbiosis with a broad spectrum of host plants (Verma \& Arya 1998; Pham et al. 2004). In contrast to the arbuscular mycorrhizal fungi (AMF) of the obligate biotrophic nature, $P$. indica and $S$. vermifera can be easily cultured on synthetic media (Varma et al. 2001; Kost \& Rexer 2013). These fungi colonize roots; form pear-shaped spores within the cortex, and does not enter vascular tissue and stems or leaves of plants. The ability of $P$. indica and $S$. vermifera in improving the growth rate of various host plants is well documented. Endophytic root colonization by this fungus enhances growth of the host plants (Sahay \& Varma 1999; Varma et al. 1999; Rai et al. 2001; Kumari et al. 2003; Peskan-Berghoefer et al. 2004; Waller et al. 2005; Druege et al. 2007; Das et al. 2012; Franken 
2012; Varma et al. 2012; Unnikumar et al. 2013). $S$. vermifera increased plant growth in Nicotiana attenuata (Barazani et al. 2005) and plant cell growth in suspension cultures of Linum album (Baldi et al. 2008). Beyond stimulating effects in biomass production, $P$. indica apparently supports its host by protecting it from pathogenic fungi (Waller et al. 2005). Ghahfarokhi and Goltapeh (2010) demonstrated that $P$. indica and $S$. vermifera were the most potent agents for the biocontrol of root plant pathogen Gaeumannomyces graminis var. tritici. In this study, we examined whether $P$. indica and $S$. vermifera influence the growth and development of some members of the family Brassicaceae.

\section{MATERIALS AND METHODS}

Fungal solid culture of $\boldsymbol{P}$. indica and $\boldsymbol{S}$. vermifera Endophytic fungi ( $P$. indica, $S$. vermifera) were obtained from Department of Plant Pathology, Tarbiat Modares University, Tehran, Iran (Prof. Mohammadi Goltapeh). These fungi were maintained on Kaefer's medium (Kaefer 1977). The plates were inoculated with actively growing mycelium and then incubated at $25^{\circ} \mathrm{C}$ for a week in the dark and stored at $4{ }^{\circ} \mathrm{C}$ for further use.

\section{Fungal liquid culture of $P$. indica and $S$. ver- mifera}

Mycelial liquid cultures were prepared in $500 \mathrm{ml}$ flasks containing $200 \mathrm{ml}$ of autoclaved Kaefer's liquid medium and inoculated with four $10 \mathrm{~mm}$ mycelia discs cut from 10-day-old solid cultures of $P$. indica or S. vermifera. Culture flasks were kept on a shaker $(2.42 \mathrm{~Hz})$ and incubated for 15 days at room temperature $\left(25 \pm 1^{\circ} \mathrm{C}\right)$ until a dense mycelial suspension was generated. Then, the cultures were stored at $4{ }^{\circ} \mathrm{C}$ until they were used for the pot culture experiment.

\section{Pot culture experiment}

$P$. indica and $S$. vermifera were investigated for their ability to grow and develop symbiosis with Brassica oleracea (cabbage), Brassica napus (rapeseed), Brassica nigra (black mustard), Lepidium sativum (Persian broadleaf cress), Matthiola incana (hoary stock 'Cheerful White') and Descurainia so- phia (flixweed). Pot culture experiment was conducted using a completely randomized design in four replications (eight plants for each species). Seeds of species were surface-sterilized by soaking in $1 \%$ sodium hypochlorite for $1 \mathrm{~min}$, rinsed thrice in sterile distilled water, and placed in perlite for germination. After 4-10 days when the plumules and radicles appeared, two germinated seeds were transferred to each pot. Pots were filled with a substrate containing 2:1:1 sterile mixture of sand, peat and perlite of the following chemical properties: $\mathrm{pH}$ 7.12, EC $0.9 \mathrm{dS} / \mathrm{m}$, organic carbon $0.7 \%$, total $\mathrm{N} 0.3 \%$, available phosphorus $8.2 \mathrm{mg} / \mathrm{kg}$ and potassium $285 \mathrm{mg} / \mathrm{kg}$. Pots were placed in a greenhouse at $18^{\circ} \mathrm{C}$, and a photoperiod of $16 / 8 \mathrm{~h}$ light/dark.

Fungal mycelia from liquid culture were washed with an excess of distilled water to completely remove medium and then mycelium was crushed in a blender for $10 \mathrm{~s}$. For inoculation, $1 \mathrm{~g}$ of crushed mycelia was added to germlings $24 \mathrm{~h}$ after potting. Efforts were made to keep the root system in direct contact with the fungal inocula (Kumari et al. 2003; Varma \& Schuepp 1995). Plant morphology and height as well as shoot and root dry weights were analyzed after 75 days.

For microscopic observations, the roots were washed thoroughly under running tap water and cut into $1 \mathrm{~cm}$ pieces. Segments were stained following the techniques described by Phillip and Hayman (1970) and Dickson et al. (1998). The root-pieces were examined under a microscope at a magnification of 10-60 X.

The percentage of root colonization was determined with the method proposed by Giovannetti and Mosse (1980). For each plant species, 10 roots were selected randomly from the stained roots, and then each selected root was divided into 10 pieces. The percentage of colonization was calculated by the presence of chlamydospores in each piece as follows (Rai et al. 2001):

$$
\text { Percent colonization: } \frac{\text { No. of root segments colonized }}{\text { Total no. of segments observed }} \times 100
$$

\section{Statistical analysis}

The collected data were statistically computed using the software SAS 6.12. Data were subjected to analyses of variance and treatment means were 
compared by approximate Duncan's multiple-range tests at $\mathrm{p} \leq 0.05$.

\section{RESULTS}

Microscopic inspection of the roots inoculated with $P$. indica and $S$. vermifera showed a high number of chlamydospores in root cells (Fig. 1). The percentage of colonized roots differed among plant species (Table 1). The highest colonization values 68 and $63 \%$ were found in B. oleracea inoculated with $P$. indica and $S$. vermifera, respectively, followed by $P$. indica (49\%) and B. nigra. A much lower percentage of colonized roots were found in L. sativum, D. sophia and M. incana (30-15\%). The percent of colonization was mostly similar for two fungi; only B. oleracea and D. sophia were colonized more intensively by $P$. indica.

Table 1. Effect of roots inoculation with $P$. indica and $S$. vermifera on plant height $(\mathrm{cm})$, shoot and root dry weight (g) and root colonization (\%) in six species of family Brassicaceae in pot culture experiment. Percentages connected with plant height, shoot and root dry weights were calculated taking controls as $100 \%$. In parentheses is the percentage increase in value relative to the control

\begin{tabular}{|c|c|c|c|c|}
\hline \multirow{2}{*}{ Plant species } & \multirow{2}{*}{ Parameters } & Piriformospora indica & Sebacina vermifera & Control \\
\hline & & Mean $\pm \mathrm{SD}$ & Mean $\pm \mathrm{SD}$ & Mean \pm SD \\
\hline \multirow{4}{*}{ Brassica oleracea } & Plant height & $26.63 \pm 2.11^{\mathrm{a}}(17 \%)$ & $29.08 \pm 2.81^{\mathrm{a}}(27 \%)$ & $22.85 \pm 2.09^{b}$ \\
\hline & Shoot dry weight & $2.94 \pm 0.32^{\mathrm{a}}(41 \%)$ & $2.54 \pm 0.32^{\mathrm{a}}(22 \%)$ & $2.09 \pm 0.05^{\mathrm{b}}$ \\
\hline & Root dry weight & $0.52 \pm 0.12^{\mathrm{a}}(41 \%)$ & $0.51 \pm 0.07^{\mathrm{a}}(38 \%)$ & $0.37 \pm 0.02^{\mathrm{b}}$ \\
\hline & Root colonization & $68 \pm 3.27^{\mathrm{a}}$ & $63 \pm 3.83^{\mathrm{b}}$ & $0 \pm 0^{\mathrm{c}}$ \\
\hline \multirow{4}{*}{ Brassica napus } & Plant height & $38.20 \pm 3.80^{\mathrm{a}}(17 \%)$ & $41.18 \pm 4.21^{\mathrm{a}}(26 \%)$ & $32.58 \pm 2.12^{\mathrm{b}}$ \\
\hline & Shoot dry weight & $2.30 \pm 0.10^{\mathrm{b}}(17 \%)$ & $2.62 \pm 0.17^{\mathrm{a}}(34 \%)$ & $1.96 \pm 0.18^{c}$ \\
\hline & Root dry weight & $0.40 \pm 0.08^{\mathrm{a}}(82 \%)$ & $0.50 \pm 0.08^{\mathrm{a}}(127 \%)$ & $0.22 \pm 0.02^{\mathrm{b}}$ \\
\hline & Root colonization & $39 \pm 6.00^{\mathrm{a}}$ & $45 \pm 3.83^{\mathrm{a}}$ & $0 \pm 0^{\mathrm{b}}$ \\
\hline \multirow{4}{*}{ Brassica nigra } & Plant height & $59.00 \pm 8.45^{\mathrm{a}}(61 \%)$ & $54.75 \pm 13.40^{\mathrm{a}}(49 \%)$ & $36.75 \pm 1.50^{\mathrm{b}}$ \\
\hline & Shoot dry weight & $1.02 \pm 0.11^{\mathrm{a}}(76 \%)$ & $0.75 \pm 0.11^{\mathrm{b}}(29 \%)$ & $0.58 \pm 0.07^{\mathrm{c}}$ \\
\hline & Root dry weight & $0.22 \pm 0.03^{\mathrm{a}}(83 \%)$ & $0.16 \pm 0.02^{\mathrm{b}}(33 \%)$ & $0.12 \pm 0.01^{\mathrm{c}}$ \\
\hline & Root colonization & $49 \pm 3.83^{\mathrm{a}}$ & $44 \pm 5.66^{\mathrm{a}}$ & $0 \pm 0^{\mathrm{b}}$ \\
\hline \multirow{4}{*}{ Lepidium sativum } & Plant height & $23.50 \pm 3.51^{\mathrm{a}}(15 \%)$ & $21.25 \pm 0.96^{\mathrm{a}}(4 \%)$ & $20.50 \pm 0.58^{\mathrm{a}}$ \\
\hline & Shoot dry weight & $0.85 \pm 0.11^{\mathrm{a}}(44 \%)$ & $0.72 \pm 0.10^{\mathrm{ab}}(22 \%)$ & $0.59 \pm 0.06^{\mathrm{b}}$ \\
\hline & Root dry weight & $0.11 \pm 0.02^{\mathrm{a}}(0)$ & $0.12 \pm 0.03^{\mathrm{a}}(9 \%)$ & $0.11 \pm 0.02^{\mathrm{a}}$ \\
\hline & Root colonization & $20 \pm 3.27^{\mathrm{a}}$ & $15 \pm 5.03^{\mathrm{a}}$ & $0 \pm 0^{\mathrm{b}}$ \\
\hline \multirow{4}{*}{ Descurainia sophia } & Plant height & $15.00 \pm 2.71^{\mathrm{a}}(76 \%)$ & $11.00 \pm 1.41^{\mathrm{b}}(29 \%)$ & $8.50 \pm 1.73^{\mathrm{b}}$ \\
\hline & Shoot dry weight & $0.29 \pm 0.07^{\mathrm{a}}(71 \%)$ & $0.19 \pm 0.02^{\mathrm{b}}(12 \%)$ & $0.17 \pm 0.03^{b}$ \\
\hline & Root dry weight & $0.15 \pm 0.03^{\mathrm{a}}(66 \%)$ & $0.11 \pm 0.01^{\mathrm{b}}(22 \%)$ & $0.09 \pm 0.01^{\mathrm{b}}$ \\
\hline & Root colonization & $29 \pm 3.83^{\mathrm{a}}$ & $16 \pm 3.27^{\mathrm{b}}$ & $0 \pm 0^{\mathrm{c}}$ \\
\hline \multirow{4}{*}{ Matthiola incana } & Plant height & $26.53 \pm 4.83^{\mathrm{a}}(37 \%)$ & $26.75 \pm 1.73^{\mathrm{a}}(38 \%)$ & $19.35 \pm 1.70^{\mathrm{b}}$ \\
\hline & Shoot dry weight & $1.25 \pm 0.33^{\mathrm{a}}(23 \%)$ & $1.38 \pm 0.16^{\mathrm{a}}(35 \%)$ & $1.02 \pm 0.13^{\mathrm{a}}$ \\
\hline & Root dry weight & $0.32 \pm 0.03^{\mathrm{a}}(7 \%)$ & $0.35 \pm 0.03^{\mathrm{a}}(17 \%)$ & $0.30 \pm 0.03^{\mathrm{a}}$ \\
\hline & Root colonization & $28 \pm 3.27^{\mathrm{a}}$ & $30 \pm 2.31^{\mathrm{a}}$ & $0 \pm 0^{\mathrm{b}}$ \\
\hline
\end{tabular}

Values within a row followed by the same letter are not significantly different from each other according to Duncan's Multiple Range Test at the $\mathrm{p} \leq 0.05$ levels. 

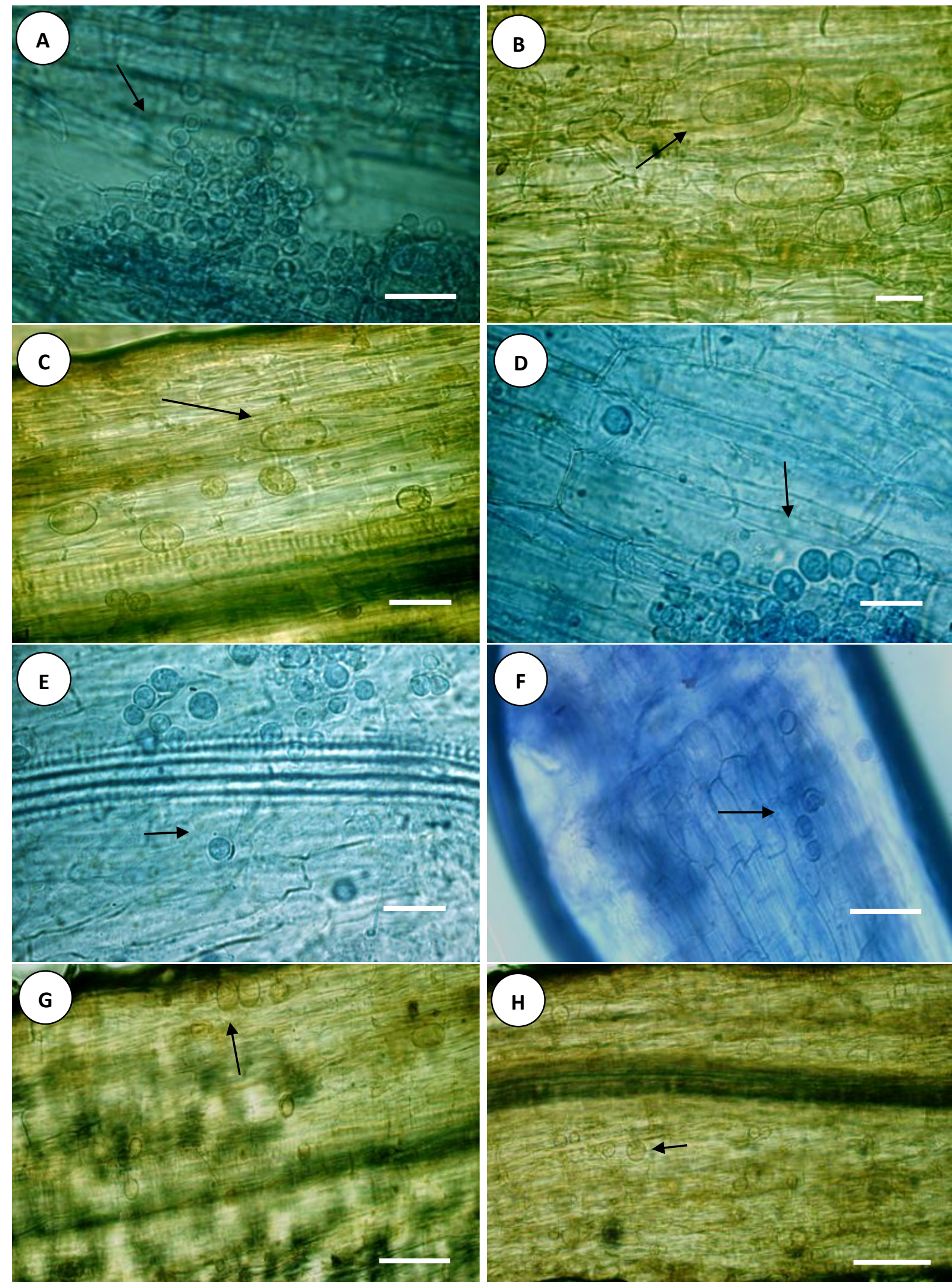

Fig. 1. Endophytic fungi in roots of Brassicaceae. A - P. indica in B. oleracea (Bar $=40 \mu \mathrm{m})$. B, C - S. vermifera in B. nigra $($ Bars $=10 \mu \mathrm{m}, 20 \mu \mathrm{m})$. D $-P$. indica in B. napus $(\mathrm{Bar}=20 \mu \mathrm{m})$. E - P. indica in D. sophia $(\mathrm{Bar}=20$ $\mu \mathrm{m})$. F - P. indica in L. sativum $(\mathrm{Bar}=40 \mu \mathrm{m}) . \mathrm{G}, \mathrm{H}-\mathrm{S}$. vermifera in M. incana $(\mathrm{Bar}=40 \mu \mathrm{m}, 60 \mu \mathrm{m})$. Black arrows show chlamydospores 
Plants of all species inoculated with $P$. indica and $S$. vermifera presented better fitness with larger leaves and with more side shoots (Figs 2-7). Both the fungi significantly increased plant height of all species with the exception of $L$. sativum. Plant heights of B. oleracea and B. napus increased by 17 $27 \%$, depending on the fungus inoculated, in comparison to controls. Length of $B$. nigra and $D$. sophia was stimulated by $P$. indica by 61 and $76 \%$ in comparison to the control. Both fungi stimulated plants length similarly in $M$. incana (37$38 \%$ ) (Table 1).

All plants, with the exception of M. incana, inoculated with the above fungi had higher shoot dry weight in comparison to the control plants. The increase was highest in B. nigra and D. sophia inoculated with $P$. indica (by 76-71\%). Shoot and root dry weights of inoculated plants of $B$. oleracea were higher in comparison to controls. $P$. indica and $S$. vermifera increased shoot dry weight by 41 and $22 \%$ and root dry weight by 41 and $38 \%$ (Table 1).

Root dry weight of B. napus was most affected by $S$. vermifera $(127 \%$ increase) and $P$. indica $(82 \%$ increase). Shoot and root dry weight of $B$. nigra was most affected by $P$. indica (76 and $83 \%$ increase, respectively) in comparison to controls (Table 1). Root dry weight of L. sativum and M. incana was not affected by fungal inoculation.

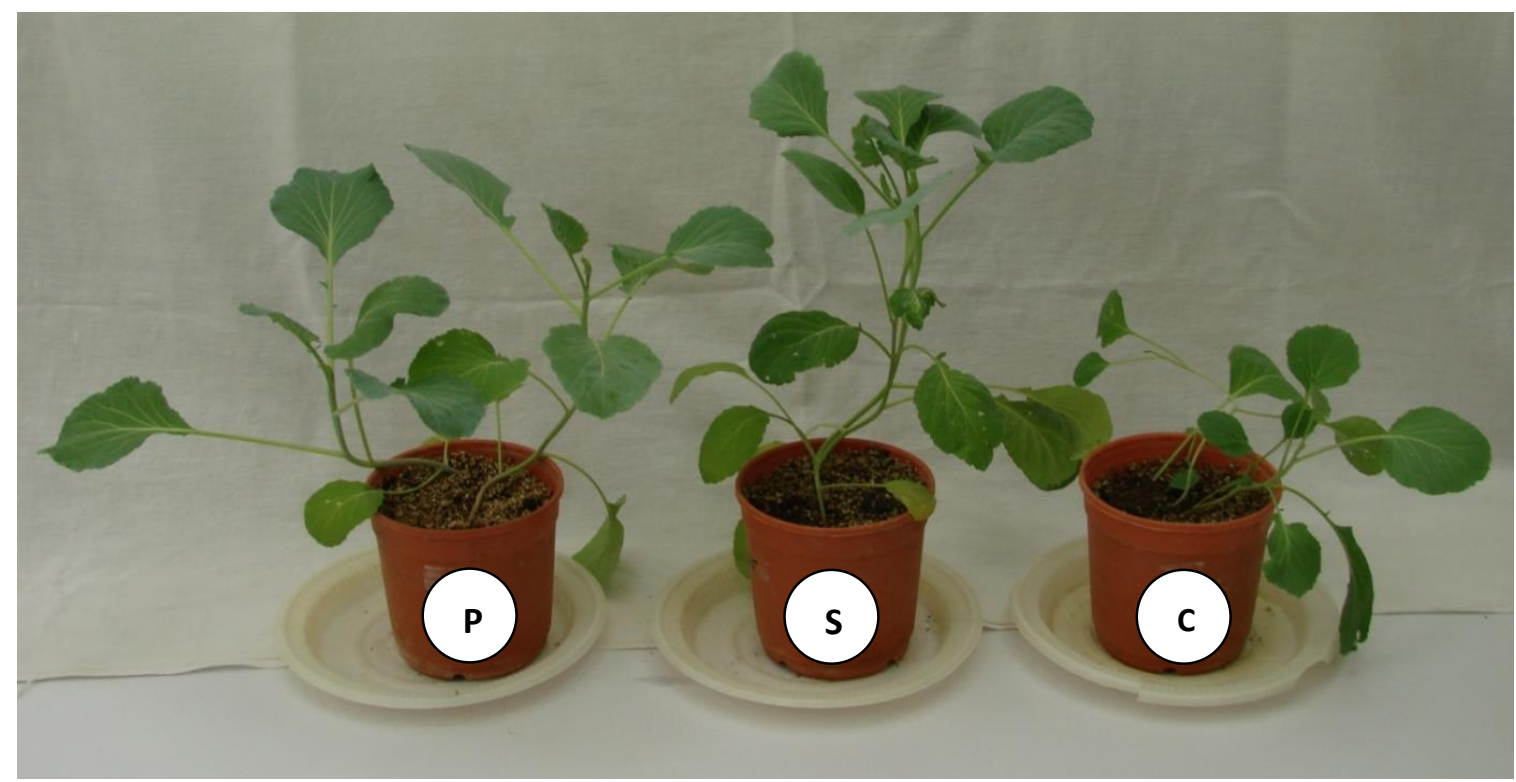

Fig. 2. Effect of $P$. indica and S. vermifera on growth of B. oleracea. P - Piriformospora indica, S - Sebacina vermifera and $\mathrm{C}$ - control
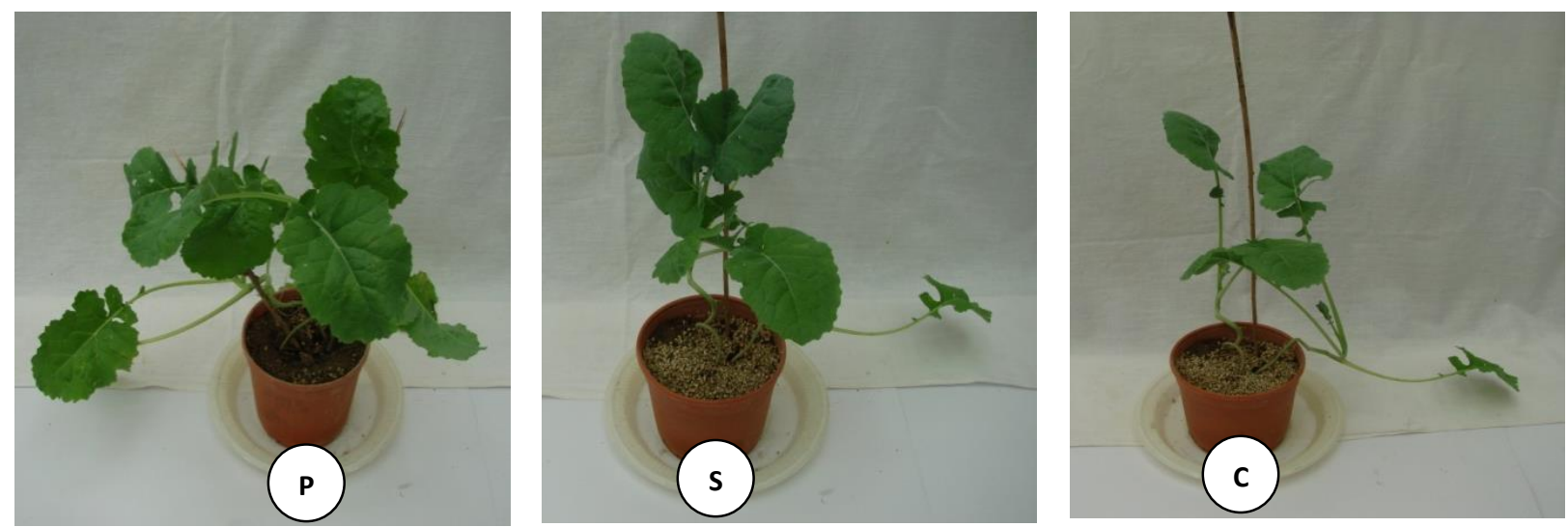

Fig. 3. Effect of P. indica and S. vermifera on growth of B. napus. P - Piriformospora indica, S - Sebacina vermifera and $\mathrm{C}$ - control 


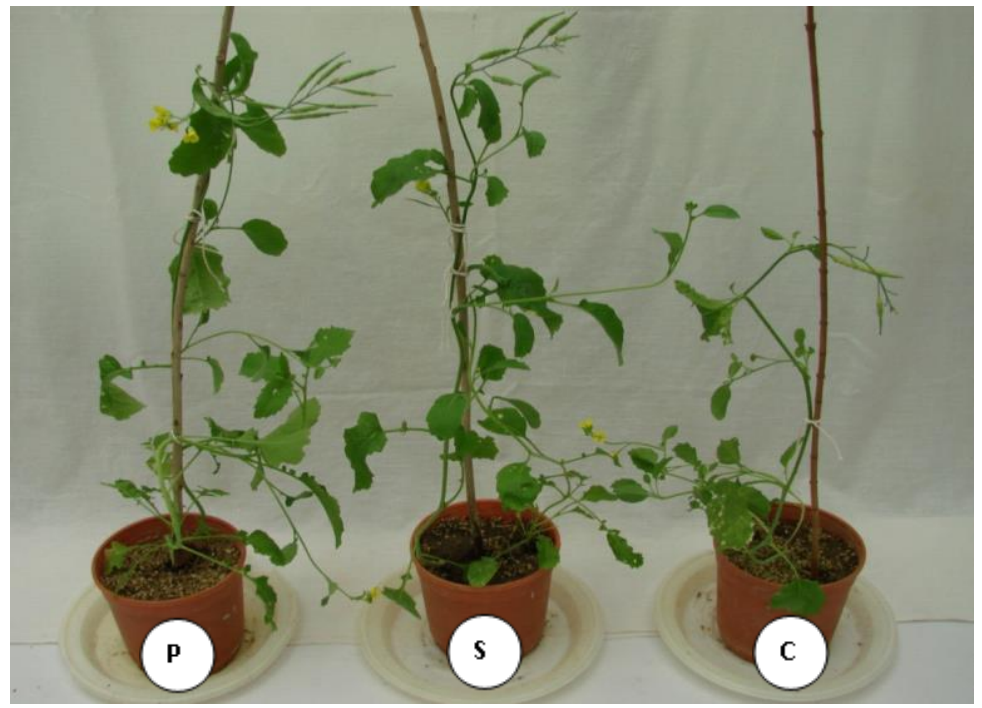

Fig. 4. Effect of $P$. indica and S. vermifera on growth of B. nigra. P - Piriformospora indica, S - Sebacina vermifera and $\mathrm{C}$ - control

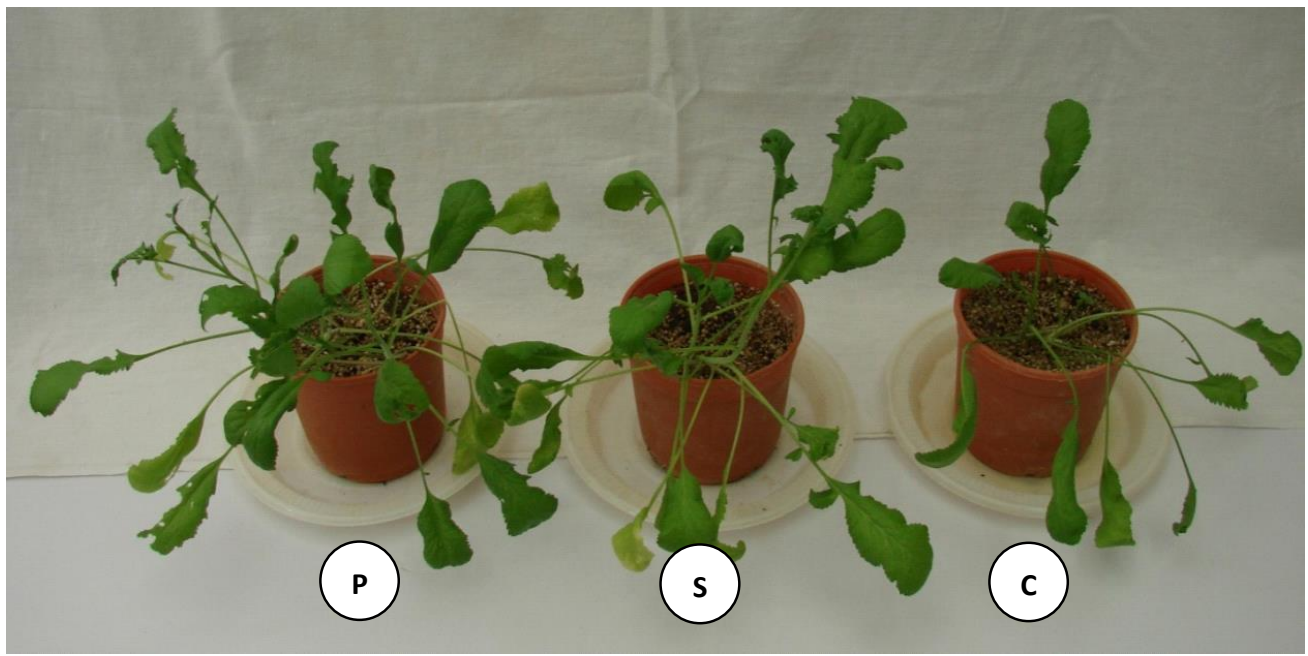

Fig. 5. Effect of $P$. indica and $S$. vermifera on growth of L. sativum. P - Piriformospora indica, S - Sebacina vermifera and $\mathrm{C}$ - control

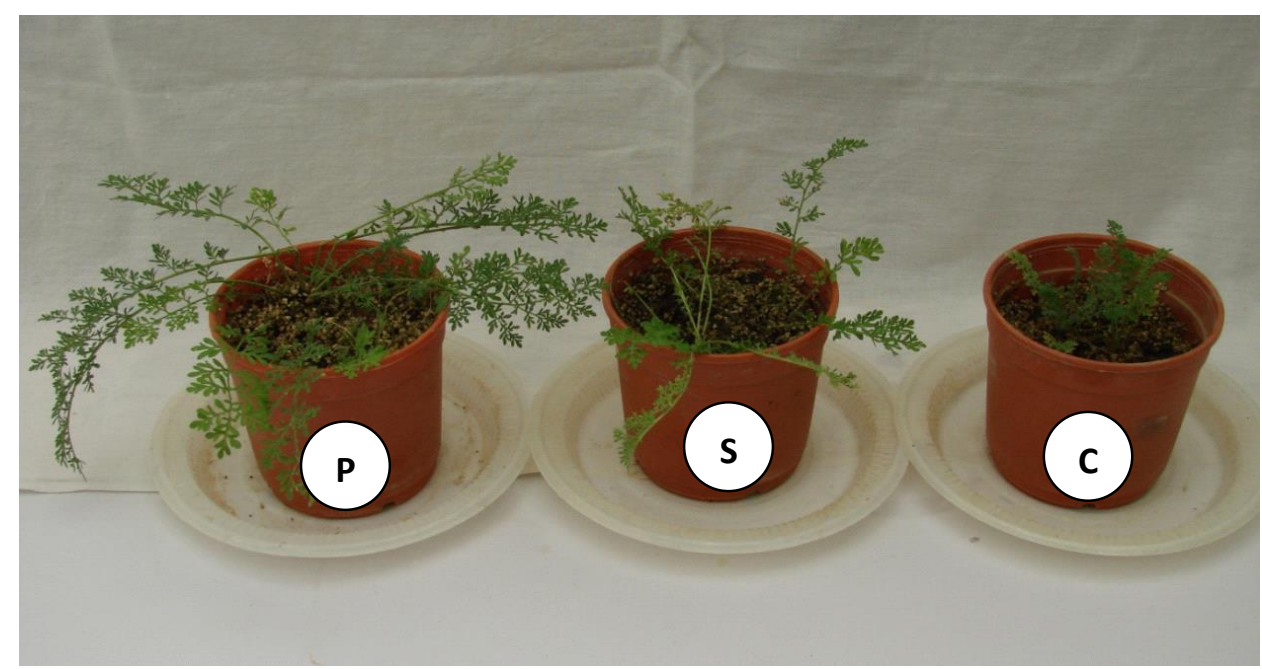

Fig. 6. Effect of P. indica and S. vermifera on growth of D. sophia. P - Piriformospora indica, S - Sebacina vermifera and $\mathrm{C}$ - control 


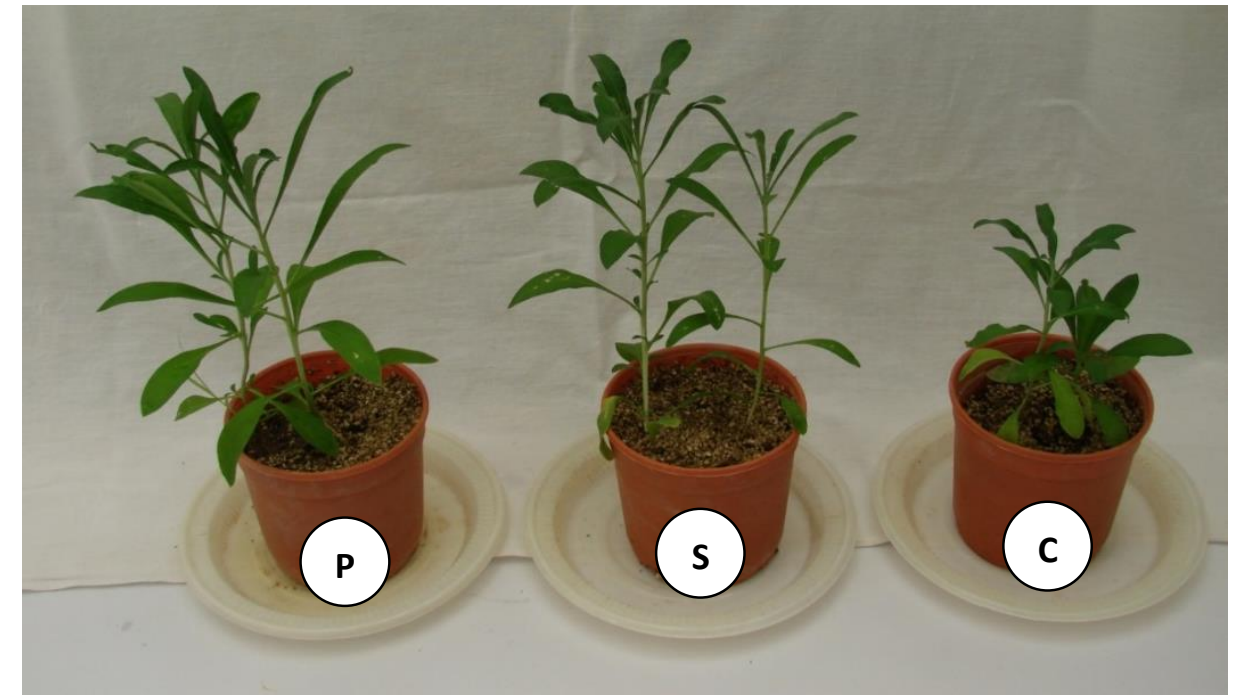

Fig. 7. Effect of $P$. indica and S. vermifera on growth of M. incana. P - Piriformospora indica, S - Sebacina vermifera and $\mathrm{C}$ - control

Taking into account plant morphology and shoot and root dry weight, B. oleracea, B. nigra, L. sativum and D. sophia were more stimulated by $P$. indica and B. nigra, and M. incana by S. vermifera. The weakest reaction was found in $L$. sativum where only shoot dry weight was influenced by $P$. indica. At the same time, roots of this plant were 3-4 times less colonized than roots of $B$. oleracea.

\section{DISCUSSION}

Rhizosphere beneficial microorganisms increase the growth of plants through facilitation of the nutrient's uptake by either increasing the extent of roots or solubilizing macronutrients such as phosphorus or sulphur (López-Bucio et al. 2007).Various fungi colonizing roots have positive effects on host performance through the production of growthpromoting substances (Clay 1984; Jumpponen 2001).

The endophytic interaction of $P$. indica with plant roots is accompanied by an enormous acquisition of nitrogen and phosphorous from the environment. Experiments using ${ }^{32} \mathrm{P}$ have shown that $P$. indica plays an important role in the acquisition of phosphorus by the roots especially in the arid and semi-arid regions (Yadav et al. 2010; Varma et al. 2012).
In this study, inoculation with $P$. indica and $S$. vermifera increased height of all plants, except of L. sativum and shoot and/or root dry weight except for L. sativum and M. incana. The more intense root proliferation in inoculated plants has been attributed to the synthesis of phytohormones (Singh et al. 2000; Varma et al. 2001). Sirrenberg et al. (2007) suggested that auxin produced by $P$. indica affects root growth and it is responsible for, or at least contributes to, the beneficial effect of fungus on its host plants. Vadassery et al. (2008) stated that $P$. indica produces low amounts of auxins and relatively high level of cytokinins, therefore cytokinin levels are higher in colonized roots of Arabidopsis thaliana compared with the uncolonized roots of controls. Our results are in agreement with those of Kumari et al. (2003), who showed that B. oleracea var. capitata (cabbage), Spinacia oleracea (spinach) and $B$. juncea (mustard) were colonized with $P$. indica. Members of the Brassicaceae (e.g. A. thaliana) and Chenopodiaceae are known to be non-host plants for mycorhitic fungi, but they are able to interact with $P$. indica (Peskan-Berghoefer et al. 2004; Pham et al. 2004). The results of our experiments clearly demonstrate high effectiveness of $P$. indica and $S$. vermifera in increasing the crop growth. The shoots growth of L. sativum was not stimulated by fungi. Ghimire et al. (2009) reported that S. ver- 
mifera increased plant height, root length, and biomass production of switchgrass (Panicum virgatum L.). Varma et al. (1999) reported that inoculation with $P$. indica promotes plant growth and biomass production in maize, tobacco, poplar, artemisia, parsley and Bacopa. In our experiment, species reacted differently for applied fungi. B. oleracea, B. nigra, $L$. sativum and $D$. sophia were under stronger influence of $P$. indica and $B$. napus and $M$. incana were more influenced by $S$. vermifera. The differences in plant reaction might be attributed to the level of root colonization by the two fungi. In Baldi's et al. (2008) publication, increase of cell growth in suspension cultures of $\mathrm{Li}$ num album was dependent on the concentration of fungal cells at co-cultivation cultures. Rai et al. (2001) reported that shoot and root length, biomass, basal stem, leaf area, overall size, number of inflorescences and flowers and seed production of Spilanthes calva and Withania somnifera were enhanced in the presence of $P$. indica in roots. $P$. indica increased disease resistance and yield of the monocotyledonous plant barley (Waller et al. 2005). Barazani et al. (2005) showed that colonization of Nicotiana attenuata with $S$. vermifera and $P$. indica stimulated seed germination and plant growth. Barazani et al. (2007) concluded that $S$. vermifera increased the growth and fitness of $N$. attenuata plants through downregulation of ethylene production.

In conclusion, $P$. indica and $S$. vermifera are able to colonize $B$. oleracea, B. napus, B. nigra, L. sativum, D. sophia and $M$. incana roots and to increase plant height, dry mass of shoots and roots in most plants. However, the impact of fungi depends on the plant species.

\section{Acknowledgements}

This study was supported by Graduate School, Department of Plant Pathology, School of Agriculture, Tarbiat Modarres University, Tehran, Iran.

\section{REFERENCES}

Baldi A., Jain A., Gupta N., Srivastava A.K., Bisaria V.S. 2008. Co-culture of arbuscular mycorrhiza-like fungi (Piriformospora indica and Sebacina ver- mifera) with plant cells of Linum album for enhanced production of podophyllotoxins: a first report. Biotechnol. Lett. 30: 1671-1677. DOI: 10.1007/s10529-008-9736-z.

Barazani O., Benderoth M., Groten K., Kuhlemeier C., Baldwin I.T. 2005. Piriformospora indica and Sebacina vermifera increase growth performance at the expense of herbivore resistance in Nicotiana attenuata. Oecologia 146: 234-243. DOI: 10.1007/s00442-005-0193-2.

Barazani O., Dahl C.C.V., Baldwin I.T. 2007. Sebacina vermifera promotes the growth and fitness of Nicotiana attenuata by inhibiting ethylene signaling. Plant Physiol. 144: 1223-1232. DOI: 10.1104/pp.107.097543.

Clay K. 1984. The effect of the fungus Atkinsonella hypoxylon (Clavicipitaceae) on the reproductive system and demography of the grass Danthonia spicata. New Phytologist 98: 165-175. DOI: 10.1111/j.1469-8137.1984.tb06106.x

Das A., Kamal S., Shakil N.A., Sherameti I., Oelmüller R., Dua M., Tuteja N., Johri A.K., Varma A. 2012. The root endophyte fungus Piriformospora indica leads to early flowering, higher biomass and altered secondary metabolites of the medicinal plant, $\mathrm{Co}$ leus forskohlii. Plant Signal. Behav. 7: 103-112. DOI: 10.4161/psb.7.1.18472.

Dickson S., Mandeep S.M., Smith S.M. 1998. Evaluation of vesicular arbuscular mycorrhizal colonization by staining. In: Varma A. (Ed.), Mycorrhiza Manual, pp. 77-84. Springer-Verlag, Berlin.

Druege U., Baltruschat H., Franken P. 2007. Piriformospora indica promotes adventitious roots formation in cuttings. Sci. Hort. 112: 422-426. DOI: $10.1016 /$ j.scienta.2007.01.018.

Franken P. 2012. The plant strengthening root endophyte Piriformospora indica: potential application and the biology behind. Appl. Microbiol. Biotechnol. 96: 1455-1464. DOI: 10.1007/s00253-012-4506-1.

Ghahfarokhi R.M., Goltapeh M.E. 2010. Potential of the root endophytic fungus Piriformospora indica; Sebacina vermifera and Trichoderma species in biocontrol of take-all disease of wheat Gaeumannomyces graminis var. tritici in vitro. J. Agric. Technol. 6(1): 11-18.

Ghimire S.R., Charlton N.D., Craven K.D. 2009. The mycorrhizal fungus, Sebacina vermifera, enhances seed germination and biomass production in Switchgrass (Panicum virgatum $\mathrm{L}$ ). Bioenerg. Res. 2: 51-58. DOI: 10.1007/s12155-009-9033-2. 
Giovannetti M., Mosse B. 1980. An evaluation of techniques for measuring vesicular-arbuscular mycorrhizal infection in roots. New Phytologist 84: 489-500. DOI: 10.1111/j.1469-8137.1980.tb04556.x.

Hedge I.C. 1976. A systematic and geographical survey of the old world Cruciferae. In: Vaughn J.G., MacLeod A.J., Jones B.M.G. (Eds.), The biology and chemistry of the Cruciferae. Academic Press, London, pp. 1-45.

Jumpponen A. 2001. Dark septate endophytes - are they mycorrhizal? Mycorrhiza 11: 207-211. DOI: 10.1007/s005720100112.

Kaefer E. 1977. Meiotic and mitotic recombination in $A s$ pergillus and its chromosomal aberrations. Adv. Genet. 19: 33-131.

Kost G., Rexer K.H. 2013. Morphology and ultrastructure of Piriformospora indica. In: Varma A., Kost G., Oelmueller R. (Eds.), Piriformospora indica: Sebacinales and their biotechnological applications. Springer, Germany, pp. 25-36. DOI: 10.1007/978-3-642-33802-1_2.

Kumari R., Kishan H., Bhoon Y.K., Varma A. 2003. Colonization of cruciferous plants by Piriformospora indica. Curr. Sci. 85:1672-1674.

López-Bucio J., Campos-Cuevas J.C., HernandezCalderon E., Valasquez-Bacerra C., Farias-Rodriguez R., Macias-Rodriguez L.I., Valencia-Cantero E. 2007. Bacillus megaterium rhizobacteria promote growth and alter root system architecture through an auxin and ethylene-independent signaling mechanism in Arabidopsis thaliana. Mol. Plant Microbe Interact. 20: 207-217. DOI: 10.1094/MPMI-20-2-0207.

Peskan-Berghoefer T., Shahollaria B., Giong P.H., Hehl S., Markerta C., Blanke V., Kost G., Varma A., Oelmeuller R. 2004. Association of Piriformospora indica with Arabidopsis thaliana roots represents a novel system to study beneficial plant-microbe interactions and involves early plant protein modifications in the endoplasmatic reticulum and at the plasma membrane. Physiol. Plant 122: 465-477. DOI: 10.1111/j.1399-3054.2004.00424.x.

Pham G.H., Singh A., Kumari R., Malla R., Prasad R., Sachdev M., Rexer K.H., Kost G., Luis P., Kaldorf M., Buscot F., Herrmann S., Peskan T., Oelmüller R., Saxena A.K., Declerck S., Mittag M., Stabentheinerv E., Hehl S., Varma A. 2004. Interaction of Piriformospora indica with diverse microorganisms and plants. In: Varma A., Abbott L., Werner D., Hampp R. (Eds.), Plant Surface Microbiology. Springer-Verlag, Berlin, pp. 237-265. DOI: 10.1007/978-3-540-74051-3_15.
Phillip J.M., Hayman D.S. 1970. Improved procedures for clearing roots and staining parasitic and VAM fungi for rapid assessment of infection. Trans $\mathrm{Br}$. Mycol. Soc. 55: 158-161.

Rai M., Acharya D., Singh A., Varma A. 2001. Positive growth responses of the medicinal plants Spilanthes calva and Withania somnifera to inoculation by $\mathrm{Pi}$ riformospora indica in a field trial. Mycorrhiza 11: 123-128. DOI: 10.1007/s005720100115.

Sahay N.S., Varma A. 1999. Piriformospora indica: a new biological hardening tool for micropropagated plants. FEMS Microbiol. Lett. 181: 297-302. DOI: 10.1111/j.1574-6968.1999.tb08858.x.

Singh A., Sharma J., Rexer K.H., Varma A. 2000. Plant productivity determinants beyond minerals, water and light. Piriformospora indica: a revolutionary plant growth promoting fungus. Curr. Sci. 79: 15481554.

Sirrenberg A., Gobel C., Grond S., Czempinski N., Ratzinger A., Karlovsky P., Santos P., Feussner I., Pawlowski K. 2007. Piriformospora indica affects plant growth by auxin production. Physiol. Plant. 131: 581-589. DOI: 10.1111/j.1399-3054.2007.00983.x.

Unnikumar K.R., Sowjanya Sree K., Varma A. 2013. Piriformospora indica: a versatile root endophytic symbiont. Symbiosis 60: 107-113. DOI: 10.1007/s13199-013-0246-y.

Vadassery J., Ritter C., Venus Y., Camehl I., Varma A., Shahollari B., Novák O., Strnad M., Ludwig-Müller J., Oelmüller R. 2008. The role of auxins and cytokinins in the mutualistic interaction between Arabidopsis and Piriformospora indica. Mol. Plant Microb. Interact. 21: 1371-1383. DOI: 10.1094/MPMI21-10-1371.

Varma A., Bakshi M., Lou B., Hartmann A., Oelmueller R. 2012. Piriformospora indica: A Novel Plant Growth-Promoting Mycorrhizal Fungus. Agric. Res. 1(2): 117-131. DOI: 10.1007/s40003-0120019-5.

Varma A., Schuepp H. 1995. Mycorrhization of the commercially important micropropagated plants. Crit. Rev. Biotechnol. 15: 313-328. DOI: $10.3109 / 07388559509147417$.

Varma A., Singh A., Sudha Sahay N., Sharma J., Roy A., Kumari M., Rana D., Thakran S., Deka D., Bharti K., Franken P., Hurek T., Blechert O., Rexer K.H., Kost G., Hahn A., Hock B., Maier W., Walter M., Strack D., Kranner I. 2001. Piriformospora indica: A cultivable mycorrhiza-like endosymbiotic fungus. In: Mycota IX, Springer Series, Germany, pp. 123-150. 
Varma A., Verma S., Sudha Sahay N., Bütehorn B., Franken P. 1999. Piriformospora indica, a cultivable plant growth-promoting root endophyte. Appl. Environ. Microbiol. 65: 2741-2744.

Verma R.K., Arya I.D. 1998. Effect of arbuscular mycorrhizal fungal isolates and organic manure on growth and mycorrhization of micropropagated Dendrocalamus asper plantlets and on spore production in their rhizosphere. Mycorrhiza 8: 113116. DOI: $10.1007 / \mathrm{s} 005720050221$.

Verma S., Varma A., Rexer K.H., Hassel A., Kost G., Sarabhoy A., Bisen P., Bütehorn B., Franken P. 1998. Piriformospora indica, gen. et sp. nov., a new root-colonizing fungus. Mycologia 90: 896-903. DOI: $10.2307 / 3761331$.

Waller F., Achatz B., Baltruschat H., Fodor J., Becker K., Fischer M., Heier T., Heuckelhoven R., Neumann C., von Wettstein D., Franken P., Kogel K.H. 2005. The endophytic fungus Piriformospora indica re- programs barley to salt-stress tolerance, disease resistance, and higher yield. Proc. Natl. Acad. Sci. USA 38: 13386-13391.

Warcup J.H. 1988. Mycorrhizal associations of isolates of Sebacina vermifera. New Phytol. 110: 227-231.

Warwick S.I., Al-Shehbaz I.A. 2006. Brassicaceae: chromosome number index and database on CD-ROM. Pl. Syst. Evol. 259: 237-248.

Weiss M., Selosse M.A., Rexer K., Urban A., Oberwinkler F. 2004. Sebacinales: a hitherto overlooked cosm of heterobasidiomycetes with a broad mycorrhizal potential. Mycol. Res. 108: 1003-1010. DOI: 10.1017/S0953756204000772.

Yadav V., Kumar M., Deep D.K., Kumar H., Sharma R., Tripathi T., Tuteja N., Saxena A.K., Johri A.K. 2010. A phosphate transporter from the root endophytic fungus Piriformospora indica plays a role in phosphate transport to the host plant. J. Biol. Chem. 285: 26532-26544. DOI: 10.1074/jbc.M110.111021. 